\title{
Globalização multicultural, direitos universais humanos e socioambientais
}

\author{
Multicultural globalization, social environmental \\ and human universal rights
}

\begin{abstract}
Dempsey Pereira Ramos Júnior ${ }^{[a]}$, Edson Damas da Silveira ${ }^{[b]}$
[a] Mestre em Direito Ambiental pela Universidade do Estado do Amazonas (UEA), professor no curso de Graduação em Direito da UEA, Manaus, AM - Brasil, e-mail: dempsey junior@yahoo.com.br

[b] Procurador de Justiça, Mestre e Doutor em Direito Econômico e Socioambiental pela Pontifícia Universidade Católica do Paraná (PUCPR), Especialista em Desenvolvimento Regional Sustentável e Políticas Públicas, professor em cursos de Graduação, Especialização e no Mestrado em Direito Ambiental da Universidade do Estado do Amazonas (UEA), AM - Brasil, e-mail: edsondamas@mp.rr.gov.br
\end{abstract}

\section{Resumo}

O processo de globalização relaciona-se com o multiculturalismo sob uma ótica colonial europeia, em que a cultura hegemônica ocidental subjugou culturas periféricas em uma clara demonstração de racismo. A atual fase de globalização que o mundo vive refere-se mais diretamente ao modelo capitalista de economia, com sua lógica de mercado individualista, patrimonialista, privatista. Essa mesma lógica contribuiu para o surgimento do Estado Nacional, um modelo de organização política com tendência e vocação homogeneizante da sociedade, baseado em uma concepção universal de direitos, em que 
diferentes comunidades humanas, portadoras de diferentes valores e visões próprias de mundo, foram reunidas sob uma mesma ordem, unitária, em um território único e bem definido. A economia globalizada de mercado favorece o contato entre diferentes culturas, tanto dentro como fora de um mesmo Estado. O multiculturalismo é considerado uma estratégia de povos e comunidades periféricas para se defenderem do efeito homogeneizante da economia de mercado e do seu órgão político, o Estado Nacional. Há duas globalizações: a hegemônica ocidental, levada a cabo pelo sistema econômico capitalista; e a contra-hegemônica, das culturas dominadas, uma reação contra o extermínio de práticas e tradições culturais locais. O discurso dos direitos humanos é usado de forma hegemônica, direcionado para os valores do mercado capitalista, e de forma contra-hegemônica, como reação das minorias. Diante desse quadro plural, o texto mostra alguns métodos de harmonização intercultural, o papel das constituições, das estruturas estatais e dos direitos humanos, quer como instrumentos de dominação, quer como mecanismos de contra-hegemonia.

Palavras-chave: Direito Societário. Acordo de quotistas. Sociedades limitadas.

\section{Abstract}

The globalization process is related to multiculturalism under an european colonial otic, where west hegemonic cultures subjugated peripheric cultures in a clear racism demonstration. The actual globalisation stage that world lives is related more directly to the capitalist model of economy, where the market logic is individualist, patrimonialist and privatist. This same logic contributed to the emergence of the National State, a model of politic organization with an uniforming tendency and vocation of society, based upon an universal concept of rights, where different human communities, porter of different values and own visions of the world, were reunited under the same and uniform order, inside an unique and well defined territory. The globalised market economy favours the contact between different cultures, as much as in and out the same State. The multicultarilism is considered a strategy of peripherics peoples and communities to defend themselves from the uniforming effects of the market economy and its political organism, the National State. There are two globalization: the west hegemonic, conducted by the capitalist economic system; and the counter-hegemonic of the dominated cultures, a reaction against the extermination of local and cultural practices and traditions. The human rights speech is used as hegemonic 
way pointed toward the capitalist market's values, and as counter-hegemonic way like minorities reaction. Before such a plural scenario, this text shows some methods of intercultural harmonization, the constitutions, state structures and human rights roles, as such domination instruments, as counter-hegemonic mecanisms.

Keywords: Globalization. Multiculturalism. Human rights. Social environmental rights.

\section{Introdução}

Neste breve escorço iremos refletir acerca do fenômeno da globalização e suas implicações sobre as minorias vulneráveis, procurando entender ainda de que forma o estado nacional lida com as sociedades multiculturais por ele envolvidas. O discurso sobre direitos humanos também será objeto de análise, assim como a nova categoria dos direitos socioambientais, a desafiarem um processo hegemônico de dominação que passa atualmente por uma revisão de rumo.

Para descortinar o texto, entendemos o racismo e o multiculturalismo como produtos revigorados da globalização. O racismo é geralmente encarado como justificativa ideológica e consequência prática do imperialismo e do colonialismo. Está relacionado com a ascensão do domínio ocidental capitalista do mundo, que proclamou a superioridade da cultura e da religião ocidentais e justificou sua missão de levar a civilização e o cristianismo a povos bárbaros e pagãos. Denegrir deliberadamente outras culturas causou um sentimento de inferioridade entre esses povos. Essa atitude deturpou e estereotipou culturas.

O multiculturalismo, por sua vez, pertence ao período contemporâneo da globalização e é encarado como instrumento de luta contra o racismo, de modo a assegurar um sistema social e político mais justo. A relação entre globalização e multiculturalismo é, portanto, ambígua. Em certo nível, a globalização põe em contato diferentes culturas. Os Estados surgidos em meio ao processo de migrações passaram a ter em 
seu território diversos povos sob uma soberania e fronteiras comuns. De igual forma, as migrações contemporâneas conduzem ao desenvolvimento de Estados multiculturais.

Mesmo dentro de um Estado, a globalização reforça os contatos entre seus diferentes povos, na medida em que a busca por novas matérias-primas trazem povos nativos para dentro do mercado e, consequentemente, para dentro da esfera estatal. A atual preocupação com a identidade reconheceu e deu proeminência a identidades dentro de Estados que tendiam a ver a si mesmos como étnica e culturalmente homogêneos, dando assim novo impulso ao multiculturalismo.

Isso altera o contexto no qual opera o multiculturalismo, trazendo-o para dentro dos limites do Estado, deixando de ser apenas um choque entre culturas de povos geograficamente diferentes. Hoje existe maior respeito por outras culturas. O direito internacional entabulado pelos Estados nacionais e a economia global promovem a conscientização étnica e cultural, como um mecanismo de defesa. As culturas dominadas não são tão vulneráveis como eram antes; têm agora seus próprios Estados soberanos e algumas delas são bem-sucedidas economicamente, a tal ponto que conseguem desafiar as pretensões de superioridade das culturas ocidentais, como no "debate sobre valores asiáticos" (GHAI, 1994; LANGLOIS, 2001).

Por outro lado, devemos reconhecer a influência homogeneizadora do capitalismo e dos mercados globais sobre as culturas. Há muitas evidências de que capitalismo de mercado labora para quebrar e eventualmente destruir a propriedade comunal ou comum da terra e, com isso, os laços e a coesão da comunidade. Ele introduz novos valores que desenraizam modos tradicionais de pensar e agir. Destrói a família nuclear ou ampliada, em torno da qual estão estruturados valores e rituais centrais da cultura. Conduz a novas formas de trabalho e a novos modelos de organização. Mais ainda: hoje em dia estamos submetidos à poderosa influência dos meios de comunicação social, do cinema e da publicidade internacionais, financiados por marcas e outras formas de direitos de propriedade intelectual. 
Porém, alguns têm defendido que o capitalismo não precisa ter esse tipo de impacto sobre uma sociedade e os seus valores tradicionais. Os chineses e outras comunidades no Extremo Oriente teriam desenvolvido e sustentado economias capitalistas sem serem obrigados a abdicar dos valores confucionistas; pelo contrário, o próprio confucionismo teria sido a matriz fundamental de organização desse capitalismo (REDDING, 1990).

No entanto, é pouco provável que o capitalismo possa se desenvolver dessa forma além de um patamar de algum modo rudimentar, e é claro que quando as empresas do Extremo Oriente ampliam sua ação ao espaço nacional ou global, elas inevitavelmente alteram os seus modelos de organização, de financiamento e de tomada de decisão (GHAI, 1993).

O argumento de que o capitalismo é compatível com várias formas de cultura parece ser insustentável. A globalização modificou de forma fundamental as culturas de muitas regiões periféricas. Ela estabeleceu um novo quadro dentro do qual as culturas podem coexistir, no qual predominam as ideias ocidentais de economia, indivíduo, comunidade e Estado. Existem, contudo, resistências a esse quadro.

É necessário que se faça uma distinção crucial entre globalização hegemônica, dominada pela lógica do capitalismo neoliberal, e globalização contra-hegemônica, ou seja, as iniciativas locais-globais de grupos sociais subalternos e dominados no sentido de resistir à opressão, à descaracterização e à marginalização produzidas pela globalização hegemônica (SANTOS, 2000).

A questão deve ser colocada da seguinte maneira: é possível unir o que a globalização hegemônica separa e separar o que a globalização hegemônica une? Residirá apenas nisso a globalização contra-hegemônica? É possível contestar formas de regulação social dominante e a partir daí reinventar a emancipação social? (SANTOS, 2000).

Dentre as questões a serem abordadas está o papel das constituições, das estruturas estatais e dos direitos humanos, quer como instrumentos de dominação, quer como mecanismos de contra-hegemonia. A abordagem desses tópicos enquadra-se na estratégia geral de analisar, a partir das perspectivas da periferia, o impacto das iniciativas locais nas forças globais. 
As constituições e as estruturas estatais inserem-se claramente na categoria do local, apesar de nos casos aqui estudados refletirem também convenções internacionais. Os direitos humanos ocupam uma posição de algum modo diferente, na medida em que se tornaram centrais para a retórica da política internacional e tendo em vista que são negociados internacionalmente, a par com uma crescente indústria global de produção e vigilância desses direitos, equipada de algumas sanções e poderes de intervenção.

Existem muitos conflitos, resistências, lutas e coligações agrupadas em torno do cosmopolitismo e do patrimônio comum da humanidade, demonstrando que aquilo a que chamamos globalização é na verdade um conjunto de arenas de interação transnacional. Nessas arenas, o multiculturalismo emancipatório e as formas alternativas de justiça e cidadania que se opõem, em particular, à diferenciação desigual da identidade, à dominação e ao patriarcado apresentam-se como os mais destacados. Os direitos humanos possuem um potencial revolucionário, incluindo a construção de redes baseadas em direitos humanos e iniciativas locais.

A partir de uma posição de proximidade crítica, o texto aponta problemas em relação a alguns pressupostos que estão na base das estratégias contra-hegemônicas. Isso se deve à diversidade de situações geradas pela globalização e para que se alerte contra a crença de que possam existir soluções universais para os desafios da globalização.

Contra esse risco de universalização de soluções, é possível que algumas iniciativas que se apresentam como alternativas ao capitalismo global sejam, elas próprias, também uma forma de opressão. Por outro lado, uma iniciativa que em um dado país, em um dado momento, é vista como contra-hegemônica pode ser vista em outro país ou momento como hegemônica.

Tal como a ciência, não será a emancipação social de natureza multicultural, definível e validável apenas em certos contextos, lugares e circunstâncias? O que é emancipação social para um grupo social, ou num dado momento histórico, pode ser considerado regulação ou mesmo opressão social para outro grupo social ou em um momento histórico 
seguinte ou anterior? Todas as lutas contra a opressão, quaisquer que sejam os seus meios e objetivos são lutas pela emancipação social? Há graus de emancipação social? É possível a emancipação social sem a emancipação individual? Emancipação social para quem e para quê, contra quem e contra o quê? (SANTOS, 2000).

\section{Direitos humanos individuais, hegemônicos e contra-hegemônicos}

A complexidade e as contradições da globalização permitem que as suas ideologias, instituições e processos sejam usados tanto para facilitar quanto para combater a globalização. Isso é especialmente óbvio no caso dos direitos humanos. Os direitos humanos tornaram-se uma área de elevada contestação, com uma multiplicidade de normas e convenções regionais e internacionais, uma pluralidade de mecanismos de aplicação ou de fiscalização, com distintas justificações políticas ou morais para a primazia dos direitos, e modos de contestação ao próprio conceito de direito (GHAI, 2001).

O conceito de direitos humanos, formulado juridicamente como prerrogativa, é geralmente aceito como tendo uma origem ocidental. A tradição dominante de direitos humanos - direitos civis e políticos vem da filosofia ocidental e está intimamente ligada ao liberalismo, ao individualismo e ao mercado. Os direitos são inerentes ao indivíduo e protegem-no das ações do Estado, não de atores ou de empresas privadas. O predomínio contemporâneo da ideologia e da retórica dos direitos humanos é frequentemente encarado como um instrumento de dominação ocidental, fornecendo um apoio fundamental à globalização.

Seguem-se algumas das formas pelas quais se encara o regime de direitos humanos como uma afirmação da hegemonia ocidental:

- pela noção de universalismo, os direitos humanos permitem que os valores ocidentais se disfarcem de universais, denegrindo assim outras culturas e valores, particularmente na medida em que prejudicam a economia de mercado; 
- a noção de direitos humanos, considerados superiores a outros direitos, reivindicações ou políticas, privilegia valores ocidentais;

- as instituições e funcionários ocidentais mantêm a supremacia na interpretação dos direitos, por intermédio de decisões adjudicatórias e de processos educacionais;

- os valores promovidos por intermédio dos direitos humanos favorecem a globalização das economias: direitos de propriedade (hoje em dia amplamente difundidos), igualdade (desencorajando a discriminação contra não cidadãos), inclusão de empresas nas categorias de beneficiárias de direitos (mas não de deveres), liberdade contratual, poderes judiciários independentes, etc.;

- enfraquecimento do Estado e reforço da sociedade civil/empresas, definição de um papel circunscrito para o Estado beneficiando assim os já favorecidos (também pelo questionamento do status dos direitos econômicos, sociais e culturais como direitos - a concepção dos direitos é em grande parte determinada por intelectuais e o Ocidente tem os recursos para financiar os intelectuais e os seus centros de aprendizado);

- ampliação do âmbito das intervenções em outros Estados por meio de organizações não governamentais internacionais;

- permitir sanções contra outros Estados ou intervenções "humanitárias";

- seletividade ou dualidade de critérios que permitem uma utilização oportunista dos direitos, condenando Estados hostis ao Ocidente (como o Irã), mas ignorando ou passando ao largo do cadastro vergonhoso dos seus aliados (a Indonésia de Suharto), com o apoio dos meios de comunicação ocidentais;

- possibilidade, para um Estado poderoso, de sair impune de violações de direitos (como acontece regularmente com os Estados Unidos), em parte graças à sua hegemonia sobre as instituições internacionais. O mesmo não se passa com Estados fracos. 
Da mesma forma, os direitos humanos podem e têm sido usados como contra-hegemonia das seguintes formas:

- os movimentos independentistas no período pós-guerra apoiaram-se na linguagem dos direitos, em particular na da autodeterminação;

- desafiando a noção de universalidade dos valores ocidentais e promovendo outros valores (o debate sobre os valores asiáticos);

- usando argumentos sobre o relativismo cultural para demonstrar a especificidade cultural dos direitos humanos;

- incutindo noções de culturas diferenciais no regime de direitos humanos;

- conquistando mais espaço para derrogações e limitações dos direitos;

- denegrindo, de modo abrangente, a ideia de direitos, por intermédio, por exemplo, da referência à primazia dos deveres ou à primazia da comunidade;

- desprestigiando os direitos por intermédio de afirmações da soberania estatal;

- procurando métodos mais democráticos para a formulação dos direitos;

- expandindo a noção dos direitos, isto é, autodeterminação, direito dos povos indígenas, direitos das minorias e migrantes, direito ao desenvolvimento, direitos econômicos, sociais e culturais, e direitos relativos à diferença sexual; esses direitos desafiam a tradição até agora dominante dos direitos civis e políticos, alguns destes intimamente relacionados às economias de mercado;

- usando os direitos para a construção de redes (exemplos especialmente bem-sucedidos são os das campanhas realizadas por mulheres e por povos nativos);

- desenvolvendo noções de direitos coletivos (e defendendo que o Estado personifica o coletivo); 
- expondo a hipocrisia ocidental quanto aos direitos, demonstrando seu cumprimento assimétrico por parte dos Estados ocidentais (por exemplo, a China publicou dois relatórios oficiais documentando e criticando a realidade dos direitos nos Estados Unidos da América);

- utilizando as ideias do universalismo e da interdependência para atribuir responsabilidade aos países mais ricos;

- utilizando o conceito de direitos econômicos, sociais e culturais para resistir à ajuda e a outras condicionantes, a programas de ajuste estrutural e a diretivas da Organização Mundial do Comércio, etc.

Pela sua ambivalência, os direitos humanos são o desafio mais coerente e poderoso à ideologia da globalização. Essa última é orientada para o indivíduo, glorifica a cobiça e incentiva os não societários, ao mesmo tempo em que trata as pessoas como mercadorias (trabalho) ou como consumidores. Guiada pelo lucro, a globalização fragmenta e destrói comunidades, apropria-se de bens comuns, produz vulnerabilidade e insegurança sem valores comuns, baseando-se em monopólios e hierarquias.

Noutro giro, o regime de direitos humanos enfatiza a democracia e a participação, a solidariedade, a ação coletiva e a responsabilidade, procurando assegurar as necessidades básicas, a dignidade, o reconhecimento social e a segurança. Oferece uma visão alternativa da globalização, em que a justiça social e a solidariedade são enfatizadas.

$\mathrm{Na}$ realidade, os direitos humanos são por vezes as únicas armas à disposição dos fracos e das vítimas de diferentes tipos de opressão e violência. Porém, na sua versão impositiva e hegemônica, o regime de direitos humanos é instrumento de homogeneização e, bem por isso, tende a suprimir culturas que não sejam dominantes na emergência da teoria moderna de direitos.

O quadro dos direitos humanos também oferece opções ao individualismo que é contrário aos valores comunitários, um tipo de cosmopolitismo, de liberdade de associação a comunidades que permite a essas 
escolher, dentro de certos limites, "retirar-se" parcialmente da cultura dominante e desenvolver a sua própria cultura. Ou seja, procurar o reconhecimento da sua própria identidade e objetivos coletivos.

As abordagens contra-hegemônicas dos direitos humanos frequentemente criticam a dualidade de critérios no cumprimento desses direitos. Mas isso não deverá ser transformado em um ataque aos direitos humanos. A abordagem mais produtiva dos direitos humanos, enquanto direitos "contra-hegemônicos", é o desenvolvimento equilibrado de um quadro de direitos. Esse pode passar pela ênfase nos problemas das vítimas da desigualdade ou da opressão (exemplos disso são as convenções internacionais sobre os povos indígenas e migrantes, mulheres e crianças), pela exploração da dimensão cultural dos direitos, promovendo direitos coletivos ou de grupo capazes de reparar injustiças do passado, levando a sério os direitos econômicos, sociais e culturais, com base na sua interdependência (como nas convenções sobre mulheres e crianças), tornando os direitos transversais às políticas e instituições de desenvolvimento e enfatizando as obrigações da comunidade internacional de proteger e assegurar direitos iguais para todos (em especial direitos econômicos e sociais).

Esse último ponto é particularmente importante na era da globalização, em que a capacidade dos Estados em garantir apoio e bem-estar social tem passado por uma acentuada erosão justificada por doutrinas neoliberais, transferindo para organizações financeiras e comerciais internacionais e para empresas transnacionais o poder de decisão sobre questões sociais e econômicas fundamentais (GHAI, 1999).

Devemos distanciar-nos das noções tradicionais de que os direitos são organizados dentro das fronteiras estatais e que a sua proteção é da responsabilidade de instituições estatais - o conceito de cidadania global confere essa responsabilidade à comunidade global, especialmente com a transferência de poder econômico e político fundamental para instituições regionais e internacionais.

De igual forma, e no mesmo sentido, pode-se invocar a conceitualização clássica dos direitos humanos como inerentes, universais e indivisíveis. A responsabilidade pela proteção dos direitos humanos pode 
também ser imputada às empresas, como um desenvolvimento lógico da ascensão do poder econômico privado.

Contudo, esses mesmos direitos também podem oferecer um enquadramento mais favorável às forças em concorrência na globalização se as suas bases conceituais forem ampliadas a partir de novos referencias teóricos, construídos com espeque nos parâmetros do que venha a se entender por autodeterminação dos povos, principalmente indígenas, bem como por direitos culturais e ao desenvolvimento.

\section{Autodeterminação}

Há evidências de que o respeito à autodeterminação de minorias, dentro do Estado contemporâneo, contribui para a coesão da organização política deste, não sendo mais a autodeterminação, por esse motivo, sinônimo de separação.

O evidente preconceito da comunidade internacional de Estados contra o uso da autodeterminação além das colônias clássicas é bem conhecido (FRANCK, 1993). A Assembleia Geral das Nações Unidas decidiu há muitos anos que a autonomia é uma manifestação de autodeterminação. O crescente envolvimento da ONU ou de consórcios de Estados na resolução de conflitos internos também ajudou a desenvolver o conceito de autodeterminação como implicando a autonomia em circunstâncias adequadas, como na Bósnia, Europa oriental e Kosovo (FRANCK, 1993; HIGGINS, 1993; ROSAS, 1993).

Entrementes, o nascimento de novos Estados após o colapso da União Soviética removeu alguns tabus contra a secessão, e a comunidade internacional parece estar avançando lentamente para algum consenso sobre a ideia de que a opressão extrema de um grupo pode justificar a secessão.

Essa posição serviu para reforçar o aspecto interno da autodeterminação, uma vez que um Estado pode derrotar a reivindicação de separação se conseguir demonstrar que respeita os direitos políticos e culturais 
das minorias. Um comentário adicional a essa doutrina, e que teve consequências importantes, diz respeito ao Supremo Tribunal Canadense, que em 1999 decidiu que, tanto à luz da Constituição canadense quanto do direito internacional, Quebec não tem qualquer direito de secessão unilateral, mas que, caso escolhesse a secessão em um referendo, Ottawa e as províncias canadenses teriam de negociar com Quebec futuros acordos constitucionais.

Entrentanto, essas regras ou entendimentos não são plenamente aceitos, e é pouco provável que consigam persuadir dirigentes na África ou na Ásia. No caso da América Latina, algumas ambiguidades da noção de autodeterminação, em relação aos direitos dos povos indígenas, têm sido questionadas, como veremos a seguir.

\section{Povos indígenas}

A Convenção 169 da OIT (BRASIL, 2004), que inegavelmente representou uma inversão na abordagem paternalista e assimilacionista da Convenção 107 da mesma organização, reconheceu as aspirações desses povos a exercer controle sobre as suas próprias instituições, modos de vida e desenvolvimento econômico e a manter e desenvolver suas identidades, línguas e religiões, dentro do contexto dos Estados em que vivem. Os seus valores culturais e religiosos, as suas instituições e formas tradicionais de controle social devem ser preservados (art. 4). O sistema de propriedade da terra e as normas para transmissão dos direitos fundiários devem ser protegidos (art. 14 e 17).

A Declaração dos Direitos dos Povos Indígenas das Nações Unidas, de 2007, vai ainda mais longe e proclama o direito dos povos indígenas à autodeterminação, segundo a qual esses povos podem estabelecer livremente o seu status político e prosseguir livremente o seu desenvolvimento econômico, social e cultural.

O princípio de autodeterminação confere a esses povos o direito de autonomia ou de autogoverno em relação a questões relacionadas a 
seus assuntos internos e locais, o que inclui atividades sociais, econômicas e culturais, e o direito a controlar a entrada de não membros. Reconhece ainda os seus direitos coletivos e o direito de preservar e de controlar as suas características políticas, econômicas, culturais e sociais distintas.

Essas ideias já estiveram na base de negociações entre os povos indígenas e os Estados onde eles vivem, com o reconhecimento não só dos seus direitos de propriedade sobre a terra (como aconteceu na Nova Zelândia e na Austrália), mas também de formas de autonomia (como aconteceu no Canadá), apesar de os governos asiáticos e africanos negarem a existência de povos indígenas nos seus Estados e de esses instrumentos terem tido aí um impacto limitado (ALFREDSON, 1998; KINGSBURY, 1999; BRÖLMANN; ZIECK, 1993; STAVENHAGEN, 1996).

A proposta de "autonomia" apresentada pelo movimento indígena do Brasil é uma forma de combater a exclusão, que, no campo das relações interétnicas, caracterizou as "comunidades excludentes/defensivas" fechadas sobre si mesmas para se defenderem da dominação (social, cultural, ambiental, agrária, política, epistemológica, etc.) do Estado como uma "comunidade exclusiva-agressiva" (SANTOS, 2000, p. 14).

\section{Direitos culturais}

Quando as Nações Unidas iniciaram o seu trabalho sobre um regime internacional de direitos, enfatizaram os direitos individuais e evitaram cuidadosamente conferir direitos a grupos, em particular direitos políticos. Hoje em dia, contudo, há tendências que defendem maior reconhecimento das bases culturais e étnicas da autonomia.

$\mathrm{O}$ art. 27 do Pacto Internacional sobre Direitos Civis e Políticos, até recentemente a mais importante disposição das Nações Unidas sobre minorias, foi redigido em termos muito limitados. Nele se pode perceber que os direitos a ter sua própria vida cultural, professar e praticar a sua própria religião e utilizar a sua própria língua, embora direitos referentes 
a minorias étnicas, religiosas ou linguísticas, são garantidos às pessoas que pertençam a esses grupos. Tais direitos não são dirigidos aos grupos.

Por outro lado, a Declaração das Nações Unidas sobre os Direitos das Pessoas Pertencentes a Minorias Nacionais ou Étnicas, Religiosas e Linguísticas, adotada pela Assembleia Geral da Organização em 1992, refletiu uma abordagem mais ampla, já que estabeleceu obrigações positivas para o Estado, determinando sua obrigação de proteger a identidade das minorias e de encorajar condições para a promoção dessa identidade. A declaração coloca especial ênfase no direito de participação das minorias, garantindo-se o de conservar suas próprias associações.

\section{Direito ao desenvolvimento}

A promoção do conceito e do tema do direito ao desenvolvimento foi uma das formas mais sustentadas do desafio do Sul às versões ocidentais de direitos humanos, baseadas essencialmente em direitos civis e políticos.

A Declaração das Nações Unidas sobre o Direito ao Desenvolvimento foi adotada após um longo e considerável esforço. Esse documento internacional afirma que o direito ao desenvolvimento é um direito humano inalienável, em virtude do qual quaisquer pessoas e todos os povos têm direito de participar do desenvolvimento econômico, social, cultural e político. Afirma também que a pessoa humana é o sujeito central do desenvolvimento e deveria ser o participante ativo e beneficiário do direito ao desenvolvimento. Impõe ao Estado o dever de formular políticas nacionais adequadas ao desenvolvimento, que visem ao aumento constante do bem-estar de toda a população.

A referida declaração cita ainda a importância de relações econômicas equitativas em âmbito internacional, de modo que é uma obrigação a cooperação entre Estados por meio de políticas de desenvolvimento eficazes e um ambiente econômico internacional favorável (parágrafo 10 da Declaração e Programa de Ação de Viena, assinado na Conferência Mundial da ONU sobre Direitos Humanos, realizada em Viena - Suíça). 
Todavia, o direito ao desenvolvimento não foi bem aceito por alguns governos ocidentais e o apoio dado em Viena deveu-se a uma estratégia de barganha, de acordo com a qual os Estados do Sul foram persuadidos a aceitar a universalidade e interdependência dos direitos.

Com efeito, o documento que proclama o Direito ao Desenvolvimento é importante para estabelecer uma definição ampla e humanística de desenvolvimento como um processo econômico, social, cultural e político abrangente, que visa ao aumento constante do bem-estar de toda a população e de todos os indivíduos e em que todos os direitos humanos e as liberdades fundamentais possam ser plenamente realizados. Estabelece uma base para a integração de várias "fileiras" de direitos, assinalando as condições sob as quais todos os tipos de direitos podem ser desfrutados.

O documento prescreve, ainda, as obrigações específicas dos Estados e da comunidade internacional que derivam do direito ao desenvolvimento, incluindo a obrigação de erradicar todas as injustiças sociais. A comunidade internacional, portanto, é intimada a levar a cabo ações coletivas para assegurar não apenas o exercício completo, mas sobretudo o reforço progressivo do direito ao desenvolvimento.

Importante esclarecer que a Declaração, por si só, dificilmente acrescenta novos direitos, e a sua utilidade como meio de equilibrar diferentes tipos de direitos, ou como enquadramento para a promoção desses direitos em um mundo globalizado com novos e poderosos atores, é demasiadamente tímida e limitada.

\section{Direitos humanos plurais}

Como consequência dos movimentos ligeiramente descritos, o regime de direitos humanos já não é centrado exclusivamente no indivíduo. Ele inclui fortes normas de justiça social, por direitos econômicos e sociais; já não é indiferente aos contrastes culturais; ataca a pobreza e a alienação; e o conceito de igualdade foi enriquecido de modo a incluir a discriminação positiva e outras formas de direitos coletivos. 
Alguns desses desenvolvimentos podem existir apenas no plano teórico, mas esse não deixa de ser um ponto de partida. É evidente nas experiências da Índia, Canadá, África do Sul e Fiji, bem com no desenho das suas ordens constitucionais, que o enquadramento dos direitos humanos pode ser usado para negociar reivindicações interétnicas e para reconhecer a diversidade de culturas e de valores de uma forma amplamente defensável e aceitável (GHAI, 2000).

Temos que os países mencionados representam não só tradições culturais e religiosas diferentes, mas partilham também uma experiência comum de esforços intensos para gerir os conflitos resultantes da sua diversidade étnica e religiosa. Além disso, trata-se de exemplos típicos de Estados nacionais com enormes disparidades de acesso a recursos, riqueza e oportunidades, o que dá origem a graves problemas de justiça social.

No que refere ao caso do Canadá, as questões que mais profundamente nos dividiram e que agitaram as nossas paixões até o delírio eram relacionadas à raça, etnicidade, religião e língua, tendo todas elas uma ressonância simbólica ubíqua (CAIRNS, 1992).

Tradicionalmente, os direitos não têm sido utilizados para enfrentar essas questões. Quando o Canadá foi constituído como Estado, em 1867, pelo British North American Act, a questão principal em discussão era a das identidades e privilégios respectivos das comunidades inglesa e francesa. Essa questão foi resolvida com a concessão de uma autonomia significativa (particularmente em relação ao direito civil e à educação) à comunidade francófona residente em Quebec, por via da federalização. Essa solução persistiu durante um período de tempo bastante considerável, mas os seus limites começaram a tornar-se aparentes há algumas décadas.

Para isso acontecer, parecem ter contribuído vários fatores: o papel crescente do Estado, que gerou controvérsia sobre as políticas sociais; uma classe profissional francófona crescente em Quebec, ressentida com o domínio econômico da comunidade de língua inglesa; a imigração de outros grupos nacionais, da Europa e especialmente da Ásia, que diluiu a proporção de francófonos e desafiou a noção das duas "raças fundadoras"; 
e a politização das first nations (povos indígenas), com as suas reivindicações econômicas e culturais.

Os canadenses pareciam estar sob a ameaça da fragmentação, mas foi a força das reivindicações francófonas, apoiadas pela ameaça do separatismo de Quebec, que deu início à busca por novas soluções constitucionais, em que uma carta de direitos (Bill of Rights) desempenhou um papel importante (CAIRNS, 1992; RUSSEL, 1993).

A Carta Canadense foi adotada apenas em 1982, mais de um século depois de o Canadá ter sido constituído como Estado federal. O objetivo principal da carta não parece ter sido a consolidação dos direitos, já que estes, em geral, eram bem protegidos pelo direito e pelas tradições da política canadense (o direito penal tem sido uma questão federal, assegurando assim a uniformidade e permitindo aos tribunais rever os processos criminais nas províncias).

O impulso para a elaboração da Carta foi dado pelo então primeiro-ministro, Pierre Trudeau, que estava preocupado com um crescente sentimento de regionalismo e queria oferecer aos canadenses uma identidade que todos pudessem abraçar. Essa identidade viria de uma Carta de Direitos. O objetivo era inspirar uma nova identidade para o Canadá como Estado bilíngue e multicultural. Em outras palavras, pretendia-se superar um provincianismo limitado. A associação de direitos com a ideia de Estado-nação decorre, naturalmente, de uma longa e antiga ascendência.

Trudeau era também um forte defensor do bilinguismo e considerava que o "universalismo" a que aspirava não poderia ser alcançado sem assegurar à minoria francófona o direito à sua língua, fora de Quebec. A questão bilíngue era um alicerce de tal forma vital da sua nova construção, que foi colocada acima da cláusula de não cumprimento por razão superior (GAGNON, 1994).

Um problema surgiu em relação à Seção 25 da Carta, que tinha por objeto preservar os costumes e as práticas aborígenes da cláusula de igualdade entre os sexos (SANDERS, 1996). Outro problema referiu-se ao multiculturalismo reivindicado pelos novos imigrantes vindos de diversas 
partes da Europa, pois não ficou claro se o multiculturalismo pressupõe a neutralidade do Estado em relação às diferentes culturas ou ao envolvimento ativo do Estado na promoção de diferentes culturas. $\mathrm{O}$ único princípio discernível foi o da tolerância ou neutralidade liberal, em que a sociedade seja formada por indivíduos livres para serem o que quisessem, do ponto de vista cultural.

\section{Por um Estado multicultural}

A crítica da teoria liberal dos direitos a partir das perspectivas do multiculturalismo reflete-se também na crítica ao Estado liberal. O argumento é o de que o Estado moderno, com sua descendência de um regime de orientação para o mercado e de homogeneização, e baseado no princípio do individualismo e da cidadania igualitária, é inerentemente incapaz de lidar com a diversidade étnica e social que caracteriza a maioria dos países.

O constitucionalismo associado ao Estado moderno preocupou-se inicialmente com os limites ao poder e com o Estado de direito, aos quais iriam se juntar a democracia e os direitos humanos. Para efeito da argumentação aqui desenvolvida, considera-se que o constitucionalismo não se ocupa, inicialmente, das relações de grupos com o Estado ou das relações entre grupos.

Considerando diferentes comunidades ou grupos que buscam o reconhecimento constitucional da sua especificidade cultural ou social imigrantes, mulheres, povos indígenas, minorias religiosas ou linguísticas, conclui-se que a busca desses grupos é pela participação em instituições já existentes da sociedade dominante, mas de uma forma que reconheça e reforce os seus diversos modos de pensar, falar e agir, em vez de os excluir, assimilar e denegrir. O que esses grupos possuem em comum é o desejo de autogoverno: governarem a si próprios de acordo com os seus próprios costumes e modos de vida (TULLY, 1995).

A Constituição moderna baseia-se no pressuposto de uma cultura homogênea, mas na prática ela foi concebida para excluir ou assimilar 
outras culturas e assim negar a diversidade. As simetrias de poder, instituições e leis que definem o Estado moderno são incongruentes com a diversidade de formas de autogoverno necessárias para uma ordem justa em Estados multiétnicos.

A necessidade uma Constituição baseada no reconhecimento mútuo da diversidade é reforçada pela observação de que não é possível fugir a Estados multiétnicos, uma vez que a alternativa de cerca de 1.500 Estados-nação não é impraticável. Uma Constituição desse tipo deveria corresponder a uma forma de conciliação da diversidade cultural e do diálogo intercultural em que os cidadãos soberanos culturalmente diversificados das sociedades contemporâneas negociassem acordos acerca das formas de se associarem ao longo do tempo.

O Estado moderno impõe a uniformidade e ignora a diversidade. O princípio de organização é a soberania estatal, que justifica a centralização do poder e remove focos de poder locais e de grupo. Essa soberania funciona sobre uma base territorial, com fronteiras rígidas. As normas para o exercício da soberania favorecem as posições das maiorias, abafando as vozes das minorias (PAREKH, 1997).

Alguns instrumentos e recomendações recentes do Conselho da Europa procuram remover a diversidade linguística e religiosa: descentralização, conselhos culturais, listas eleitorais especiais, direitos relativos à língua e outros (GHAI, 2000).

Um elemento novo, mas com influência desigual na organização espacial do governo, é a emergência de organizações regionais internacionais, nas quais a soberania nacional é substituída pela participação e capacidade de decisão no âmbito dessas organizações. Essa tendência está muito desenvolvida na União Europeia, com o seu conceito, em fase de desenvolvimento, da Europa das Regiões (BULLAIN, 1998).

De outra banda, uma limitação importante da devolução territorial de poder - circunstância em que há uma concentração regional de um grupo étnico - pode ser superada por intermédio da autonomia cultural ou coletiva, que permite dar forma aos direitos coletivos de um grupo étnico geograficamente disperso. 
Existem diferentes formas e usos de autonomia coletiva. Os direitos ou prerrogativas protegidos por esse tipo de autonomia podem ser pessoais, culturais ou políticos. Podem estar enraizados ou ser sujeitos à autoridade primordial do governo. Normalmente, consistem em direitos e prerrogativas positivos e substantivos, mas podem ser negativos, como, por exemplo, o veto. Eles constituem a base da organização comunal da política e da proteção coletiva dos direitos.

A Constituição do Chipre de 1970 é um exemplo de autonomia coletiva ampliada, enquanto a atual Constituição da Bósnia-Herzegovina combina o federalismo mais tradicional com partilhas coletivas de poder e vetos comunais. Os exemplos modernos incluem disposições nas constituições ou no direito da Estônia, Hungria, Eslovênia e Federação Russa, em que os países possibilitam a criação de conselhos para minorias nacionais, que assumem a responsabilidade pela educação e questões culturais das minorias (EIDE, 1998).

Em princípio, um conselho pode ser criado se a maioria da comunidade o desejar, expressando esse desejo pelo voto. Uma vez criado o conselho, as suas decisões vinculam os membros da comunidade em todo o território do Estado, exceto se um membro optar por não fazer parte da comunidade - o importante princípio da autoidentificação é mantido. Dentro das áreas em que lhe são atribuídos poderes, as decisões do conselho prevalecem sobre as do Estado.

No Estado de Israel vigora um regime de leis pessoais especialmente aplicadas à comunidade judaica, por meio de tribunais de 14 comunidades religiosas reconhecidas. Embora o país possua tribunais civis e militares, a jurisdição dos tribunais religiosos aplica-se às questões de casamento e divórcio. Para os judeus, a maioria das questões de direito pessoal é tratada exclusivamente nos tribunais rabínicos, enquanto os muçulmanos estão sujeitos aos tribunais que aplicam a sharia. Muito embora estejam ligados ao Estado e sejam por ele apoiados, esses tribunais são administrados independentemente do Estado. Para os muçulmanos, tais tribunais acentuaram o seu sentido de comunidade, o que reforça o argumento de autonomia cultural (JACOBSOHN, 1993). 


\section{A experiência contra-hegemônica do socioambientalismo brasileiro}

$\mathrm{Na}$ linha de resistência contra-hegemônica, contribui o Brasil com o seu particular movimento socioambientalista, resultante - em sua essência - de uma equação composta e multifacetária ainda a ser decifrada, tanto no plano da doutrina e da principiologia do direito quanto no da formulação e da implementação de políticas públicas. A essência da perspectiva socioambiental brasileira, portanto, não se resume, como poderia parecer, à soma linear e aritmética entre o "social" e o "ambiental" (LIMA, 2002).

Não se prendendo a uma definição pronta e acabada, insta compreender o fenômeno, suas origens e seus propósitos. Nessa linha de intenção, e fulcrado em pesquisa que recompõe o processo de formação do ambientalismo brasileiro, correto é identificar primeiro um movimento bissetorial constituído por associações ambientalistas e agências estatais de meio ambiente, que data de 1971 até 1985, quando então acabou se transformando num movimento multissetorial e completo, constituído agora por cinco setores ${ }^{1}$ (VIOLA; LEIS, 1995).

Dentre esses se destaca justamente o socioambientalismo, constituído por organizações não governamentais e movimentos sociais que têm outros objetivos precípuos, mas incorporam a proteção ambiental com uma dimensão relevante de sua atuação (VIOLA; LEIS, 1995). Em sentido diametralmente inverso do entendimento de que ecologia e economia deveriam ser percebidos como duas realidades antagônicas, exsurge desta feita o socioambientalismo como um realimentador positivo das preocupações com os problemas econômicos, informado sobretudo pelas questões ambientais. $^{2}$

1 Além do movimento socioambientalista, Viola e Leis (1995) acrescenta ao grupo das associações ambientalistas e das agências estatais ainda as instituições científicas e os gerentes/empresários adeptos da sustentabilidade ambiental.

2 Dito fenômeno também foi percebido por Samyra Crespo. Ver: CRESPO, S. Emergência do socioambientalismo. O Globo, São Paulo, 16 dez. 2002. 
Assim, o socioambientalismo brasileiro compreende o movimento dos seringueiros, dos indígenas, dos trabalhadores rurais sem terra, dos atingidos pelas barragens, dos moradores, assim como setores da saúde ocupacional, de defesa do consumidor e movimentos pacifistas, além de grupos desenvolvimentistas do potencial humano, movimentos feministas, sindicatos de trabalhadores urbanos e organizações não governamentais (VIOLA; LEIS, 1995).

O envolvimento da sociedade civil organizada na temática ambiental - quer direta ou indiretamente - foi, enfim, o fator determinante para o surgimento do socioambientalismo no Brasil, que reivindica cada vez mais espaço nos fóruns de debate e de decisões nacionais.

Em solo brasileiro, esse crescimento nos espaços democráticos de participação se revela importante porque a legitimidade das políticas não pode estar fundada sempre na autoridade formal, nomeada pelos critérios representativos, e sim pela governança, fortalecida pelo envolvimento pleno das partes interessadas da sociedade. A participação da sociedade civil nas decisões, principalmente da iniciativa privada e das populações mais atingidas por ações governamentais, é fundamental para gerar um controle público por meio da transparência das políticas de gestão de recursos, de modo a promover o acesso igual aos meios e fins do desenvolvimento sustentável (CAMARGO; CAPOBIANCO; OLIVEIRA, 2002). Essa participação democrática das populações diretamente atingidas nas diretrizes de políticas públicas tem se verificado com mais intensidade em território amazônico, exatamente no lócus que teve por mérito influenciar e ditar toda a política ambiental brasileira.

No campo da legalidade, o constituinte originário - a partir de 1988 - acabou por premiar a sociedade brasileira com um avançadíssimo Texto Constitucional, infelizmente muito mais produto da nossa reação às pressões da comunidade internacional do que discernimento para contribuição para a construção de um mundo melhor.

No susomencionado caderno político, tanto a Floresta Amazônica como o meio ambiente tiveram papel de destaque. A primeira, alçada à condição de patrimônio nacional, de tão relevante para a 
humanidade está a reclamar legislação específica para fins de uso racional. ${ }^{3} \mathrm{O}$ meio ambiente, por outro lado, se arvorou na condição de direito fundamental, chegando a merecer capítulo próprio, onde se encontra extensamente regulado e cuidadosamente tutelado. ${ }^{4}$

Mas para completarmos o receituário socioambiental da Amazônia falta estabelecer o liame, acrescentar justamente aquela força normativa que autoriza as ações do homem sobre a natureza. E nesse aspecto se destacam os direitos à cultura ${ }^{5}$ e dos índios em particular. ${ }^{6}$

Esta é a síntese socioambiental da Amazônia Brasileira, onde se estabeleceu uma rede de proteção aos povos tradicionais, meio ambiente e cultura, reunidos todos sob a rubrica dos direitos coletivos e difusos, nomenclaturas apressadamente concebidas para tentar suprir mais uma falha do sistema jurídico da modernidade, moldado exclusivamente para atender os direitos individuais.

\section{Considerações finais}

Os casos estudados mostram a complexidade que representa o reconhecimento político da diversidade étnica. O federalismo assimétrico tem uma enorme capacidade de responder às circunstâncias e necessidades diversas de grupos étnicos. Mas é difícil de negociar e, às vezes, de colocar em prática. A autonomia cultural pode conferir a uma comunidade assediada um sentido de identidade e coesão moral, e ajudar a preservar suas tradições. Mas como outros mecanismos assimétricos, pode dar origem a injustiças tanto para os membros da comunidade autônoma quanto para os que estão fora dela.

No caso das minorias indígenas, elas têm argumentos morais fortes em favor de um tratamento especial - poucos grupos sofreram

\footnotetext{
Art. 225, par. 4․

Capítulo VI, art. 225.

Arts. 215 e 216.

6 Art. 213.
} 
tanto quanto eles a opressão de estrangeiros, à qual são ainda vulneráveis. Contudo, as suas tradições culturais e vida comunitária ainda são muito vigorantes e têm grande afinidade com a terra e com a natureza, sem embargo do firme desejo de garantir a continuidade das suas tradições.

Alguns exemplos de reconhecimento jurídico da diversidade cultural foram impostos, em vez de terem sido buscados por grupos minoritários, como as estruturas do apartheid ou os mecanismos de "dividir para reinar" usados pelas autoridades coloniais.

Os sistemas culturais separados são também uma forma de privilegiar alguns membros de uma comunidade, como as elites tradicionais geralmente masculinas - ou os mais ricos, em detrimento de outros.

Por razões semelhantes, quando a ênfase e os esforços incidem no desenvolvimento de sistemas separados para culturas separadas, isso significa que podem estar sendo negligenciados problemas sociais urgentes, quer da comunidade, quer de toda a população.

É de se concluir que, embora o multiculturalismo de fato exija a reconsideração das ordens jurídicas e constitucionais tradicionais, não se vislumbra com clareza quais serão as reconfigurações emergentes em casos particulares, devendo cada povo interessado traçar por esforço próprio o seu desígnio e lutar politicamente pela liberdade de construir cada qual a sua respectiva pauta de direitos.

Na linha do arremate de Souza Filho (1998), o único princípio universal pensável na hipótese seria a liberdade que possibilita a cada povo viver segundo seus usos e costumes, bem como transformá-los quando necessário - em constituições nacionais rígidas, após inventar sua própria forma estatal de organização.

\section{Referências}

ALFREDSON, G. Indigenous peoples and autonomy. In: SUKSI, M. (Org.). Autonomy: applications and implications. The Hague; Boston: Kluwer Law International, 1998. p. 68-89. 
BRASIL. Constituição (1988). Constituição: República Federativa do Brasil. Brasília: Senado Federal, 1988.

BRASIL. Decreto n. 592, de 6 de julho de 1992. Promulga o Pacto Internacional sobre direitos civis e políticos. In: PINTO, A. L. de T.; WINDT, M. C. V. dos S.; CÉSPEDES, L. Legislação de direito internacional. 3. ed. São Paulo: Saraiva, 2010. p. 399-412.

BRASIL. Decreto n. 5.051, de 19 de abril de 2004. Promulga a Convenção 169 da Organização Internacional do Trabalho - OIT, sobre Povos Indígenas e Tribais. Diário Oficial [da] República Federativa do Brasil, Brasília, 20 abr. 2004. Disponível em: <http://www.planalto.gov.br/ccivil_03/_ato2004-2006/2004/ decreto/d5051.htm>. Acesso em: 26 out. 2011.

BRÖLMANN, C.; ZIECK, M. Y. A. Indigenous peoples. In: BRÖLMANN, C. et al. (Org.). Peoples and minorities in international law. Dordrecht: Martinus Nijhoff, 1993. p. 6-32.

BULLAIN, I. Autonomy and the European Union. In: SUKSI, M. (Org.). Autonomy: applications and implications. The Hague; Boston: Kluwer, 1998. p. 18-32.

CAIRNS, A. C. Charter versus Federalism: the dilemmas of constitutional reform. Montreal: McGill-Queen's University Press, 1992.

CAMARGO, A.; CAPOBIANCO, J. P. R.; OLIVEIRA, J. A. P. de (Org.). Os desafios da sustentabilidade no período pós-Rio 92: uma avaliação da situação brasileira. In: CAMARGO, A.; CAPOBIANCO, J. P. R.; OliVEIRA, J. A. P. de (Org.). Meio ambiente Brasil: avanços e obstáculos pós-Rio 92. São Paulo: ISA; Estação Liberdade; Rio de Janeiro: FGV, 2002. p. 23-42.

CANADA. British North America Act. Ottawa: Imperial Parliament, 1867. Disponível em: <http://www.justice.gc.ca/eng/pi/const/lawreg-loireg/p1t11.html〉. Acesso em: 26 fev. 2011.

CRESPO, S. Emergência do socioambientalismo. O Globo, São Paulo, 16 dez. 2002. 
EIDE, A. Cultural autonomy: concept, content, history and role in the world order. In: SUKSI, M. (Org.). Autonomy: applications and implications. The Hague; Boston: Kluwer, 1998. p. 28-51.

FRANCK, T. M. Postmodern tribalism and the right to secession in comments. In: BRÖLMMAN, C. et al. (Org.). Peoples and minorities in international law. Dordrecht: Martinus Nijhoff, 1993. p. 25-73.

GAGNON, L. The Charter and Quebec. In: BRYDEN, P. et al. (Org.). Protecting rights and freedoms: essays on the Charter's place in Canada's political, legal, and intellectual life. Toronto: University of Toronto Press, 1994. p. 45-51.

GHAI, Y. The rule of law and capitalism: reflections on the basic law. In: WACKS, R. (Org.). Hong Kong, China and 1997: essays in legal theory. Hong Kong: HKU Press, 1993. p. 43-68.

GHAI, Y. Human rights and governance: the Asia debate. São Francisco: Center for Asian Pacific Affairs, Asia Foundation, 1994. Occasional paper n. 1.

GHAI, Y. Rights, social justice and globalisation in East Africa. In: BAUER, J.; BELL, D. (Org.). The east Asian challenge for human rights. Cambridge, UK: Cambridge University Press, 1999. p. 44-69.

GHAI, Y. Universalism and relativism: human rights as a framework for negotiating interethnic claims. Cardozo Law Review, v. 21, n. 4, p. 1095-1140, 2000.

GHAI, Y. Human rights and social development: towards democratization and social justice. Genebra: UNRISD, 2001.

HIGGINS, R. Postmodern tribalism and the right to secession in comments. In: BRÖLMMAN, C. et al. (Org.). Peoples and minorities in international law. Dordrecht: Martinus Nijhoff, 1993. p. 53-91.

JACOBSOHN, G. J. Apple of gold: constitutionalism in Israel and the United States. Princeton, N. J.: Princeton University Press, 1993. 
KINGSBURY, B. The applicability of the international concept of indigenous peoples in asian rights. In: BAUER, J.; BELL, D. (Org.). The east asian challenge for human rights. Cambridge, UK: Cambridge Universiy Press, 1999. p. 59-83.

LANGLOIS, A. J. The politics of justice and human rights: southeast Asia and universalist theory. Cambridge, UK: Cambridge University Press, 2001.

LIMA, A. (Org.). 0 direito para o Brasil socioambiental. Porto Alegre: Sérgio Fabris, 2002.

ORGANIZAÇÃO DAS NAÇÕES UNIDAS - ONU. Declaração e Programa de Ação de Viena. 1993. Disponível em: <http://www.pge.sp.gov.br/centrodeestudos/bibliotecavirtual/instrumentos/viena.htm>. Acesso em: 26 fev. 2011.

ORGANIZAÇÃO DAS NAÇÕES UNIDAS - ONU. Declaração das Nações Unidas sobre os direitos das pessoas pertencentes a minorias nacionais ou étnicas, religiosas e linguísticas. 1992. Disponível em: <http://www.gddc. pt/direitos-humanos/Ficha_18.pdf>. Acesso em: 26 fev. 2011.

ORGANIZAÇÃO DAS NAÇÕES UNIDAS - ONU. Declaração sobre o direito ao desenvolvimento. In: PINTO, A. L. de T.; WINDT, M. C. V. dos S.; CÉSPEDES, L. Legislação de direito internacional. 3. ed. São Paulo: Saraiva, 2010. p. 491-494.

\section{ORGANIZAÇÃO DAS NAÇÕES UNIDAS - ONU. Declaração das Nações} Unidas sobre os direitos dos povos indígenas. 2007. Disponível em: <http:// unicrio.org.br/docs/declaracao_direitos_povos_indigenas.pdf>. Acesso em: 26 fev. 2011.

PAREKH, B. Cultural diversity and the modern State. In: DOORNBOS, M.; KAVIRAJ, S. (Org.). Dynamics of state formation: India and Europe compared. Nova Delhi: Sage, 1997. p. 17-40.

REDDING, S. G. The spirit of chinese capitalism. Berlin: W. De Gruyter, 1990. ROSAS, A. Internal self-determination. In: TOMUSCHAT, C. (Org.). Modern law of self-determination. Dordrecht: Martinus Nijhoff, 1993. p. 5-33. 
RUSSELL, P. Constitutional odyssey: can canadians become a sovereign people? Toronto: Toronto University Press, 1993.

SANDERS, D. Pre-existing rights: the aboriginal peoples of Canada. In: BEAUDOIN, G-A.; MENDES, E. (Org.). The Canadian charter of rights and freedoms. Scarborough, Ont.: Carswell, 1996. p. 16-36.

SANTOS, B. de S. Reinventing social emancipation: an overview. Boston: [s.n.], 2000. Mimeo.

SOUZA FILHO, C. F. M. de. 0 renascer dos povos indígenas para o direito. Curitiba: Juruá, 1998.

STAVENHAGEN, R. Indigenous peoples and other ethnic groups. In: EIDE, A.; HAGTVET, B. (Org.). Conditions for civilized politics: political regimes and compliance with human rights. Oslo: Scandinavian University Press, 1996. p. 62-83. TULLY, J. Strange multiplicity: constitutionalism in an age of diversity. Cambridge, UK: Cambridge University Press, 1995.

VIOLA, E.; LEIS, H. R. A evolução das políticas ambientais no Brasil, 19711991: do bissetorialismo preservacionista para o multissetorialismo orientado para o desenvolvimento sustentável. In: VIOLA, E.; LEIS, H. R. (Org.). Dilemas socioambientais e desenvolvimento sustentável. 2. ed. Campinas: Ed. da Unicamp, 1995.

Recebido: 01/03/2011

Received: 03/01/2011

Aprovado: 05/04/2011

Approved: 04/05/2011 